\title{
Ontogeny of Surfactant Proteins A and B in Human Amniotic Fluid as Indices of Fetal Lung Maturity
}

\author{
GLORIA S. PRYHUBER, WILLIAM M. HULL, IRIS FINK, MICHAEL J. MCMAHAN, AND \\ JEFFREY A. WHITSETT \\ Division of Pulmonary Biology, Children's Hospital Medical Center, and University of Cincinnati College of \\ Medicine, Cincinnati, Ohio 45267-0541
}

\begin{abstract}
Surfactant proteins A and B (SP-A and SPB) were measured in human amniotic fluid by ELISA and correlated with lecithin to sphingomyelin ratio $(\mathrm{L} / \mathrm{S})$, phosphatidylglycerol (PG), and perinatal outcome. Amniotic fluid SP-A, SP-B, and L/S increased with advancing gestation. SP-A was detected at 19 wk gestation and increased dramatically in the 3rd trimester of pregnancy. SP-B was first detectable at 31 wk gestation and increased significantly to term. SP-A was a more specific predictor of nonrespiratory distress syndrome (RDS) than L/S or SP-B; however, the sensitivity of SP-A in predicting RDS was less than $\mathrm{L} / \mathrm{S}<2.0$ (26.3 versus $82.3 \%$, respectively). In 209 pregnancies assessed within $48 \mathrm{~h}$ of delivery, the sensitivity of SP-B in predicting RDS (nondetectable SPB) was comparable to the $\mathrm{L} / \mathrm{S}$, however, $\mathrm{SP}-\mathrm{B}=0$ was frequently observed in mature infants, limiting its specificity for prediction of RDS. The greatest sensitivity and specificity were achieved with the measurement of $\mathrm{L} / \mathrm{S}<$ 2.0 and negative $P G$, which correctly predicted $100 \%$ of the infants with RDS and 94\% of those who did not develop the disorder. Measurement of SP-A or SP-B did not improve the prediction of RDS. SP-A, SP-B, and L/S were not affected by infant sex, Apgar score, rupture of membranes, size for gestational age, maternal diabetes, hypertension, or exposure to medications. SP-A, SP-B, and L/S were significantly elevated in amniotic fluid from black mothers. SP-A was significantly elevated in amniotic fluid from mothers who smoked during pregnancy. Although amniotic fluid SP-A and SP-B concentrations increased with advancing gestation, the predictive value of the $L / S$ and PG for RDS was not enhanced by the additional measurement of SP-A and/or SP-B. (Pediatr Res 30: 597$605,1991)$
\end{abstract}

\section{Abbreviations}

RDS, respiratory distress syndrome SP-A, surfactant-associated protein, $M_{r}=28000-36000$ SP-B, hydrophobic surfactant-associated protein, $M_{r}=$ 8700

$\mathrm{L} / \mathrm{S}$, lecithin to sphingomyelin ratio

PG, phosphatidylglycerol

Received January 29, 1991; accepted July 22, 1991

Correspondence and reprint requests: Jeffrey A. Whitsett, M.D., Children's Hospital Medical Center, Children's Hospital Research Foundation, Division of Pulmonary Biology, Elland and Bethesda Avenues, Cincinnati, OH 45229-2899.

Supported by the National Institutes of Health, Program Project Grant "Diabetes in Pregnancy" HD1 1725 and "Programs of Excellence in Molecular Biology" HL41496. G.S.P. is supported in part by the American Lung Association Research Training Fellowship.
[SP-A], SP-A concentration

[SP-B], SP-B concentration

In 1959, Avery and Mead described a deficiency of pulmonary surfactant in lungs of low birth weight infants dying of RDS (1). Recent investigations indicate that pulmonary surfactant is a complex mixture of phospholipids and associated proteins. Although surfactant phospholipids reduce surface tension in vitro, the phospholipid-associated proteins confer unique surface properties to the lipids (2). SP-A, an $M_{r}=28000-36000$ polypeptide, is the most abundant surfactant-associated glycoprotein. SP-A enhances the surface properties of phospholipid mixtures containing the hydrophobic proteins SP-B and SP-C. SP-A also inhibits phospholipid secretion, enhances reuptake of phospholipids by type II epithelial cells in vitro, and confers calciumdependent organization to the phospholipids (for review, see Ref. 3). SP-B is an $M_{r}=8700$ hydrophobic polypeptide that imparts biophysical properties of rapid spreading and adsorption to surfactant phospholipids (for review, see Ref. 4). The surfactant phospholipids and associated proteins are developmentally regulated, appearing in the fetal rat lung between 18 and $19 \mathrm{~d}$ of gestation and increasing until birth (5-7). Lung fluid, including surfactant, contributes to the composition of amniotic fluid. Amniotic fluid content of saturated phosphatidylcholine (lecithin), PG, and phosphatidylinositol parallel the expression of these phospholipids in the fetal lung and have been used to estimate fetal lung maturity (8-13). Human amniotic fluid content of SP-A also increases with advancing gestation and is predictive of fetal lung maturity and development of RDS (14$18)$.

RDS continues to be a major cause of morbidity and mortality in premature infants. Accurate estimates of fetal lung maturity are required for optimal perinatal-neonatal management of highrisk pregnancies. The $\mathrm{L} / \mathrm{S}$ and the presence of $\mathrm{PG}$ are routinely used to predict the development of $\operatorname{RDS}(9,11,14)$. The accuracy of the combined L/S and PG tests is approximately $90-95 \%$. A high incidence of false-negative results occurs particularly with the $\mathrm{L} / \mathrm{S}$, such that fetal lung immaturity is predicted in many cases where neonatal pulmonary function is mature. In the present study, concentrations of SP-A and SP-B in human amniotic fluid were determined by capture ELISA. The predictive value of the amniotic fluid concentration of SP-A and SP-B for neonatal pulmonary disease was compared with that of the $\mathrm{L} / \mathrm{S}$ and $\mathrm{PG}$.

\section{MATERIALS AND METHODS}

Amniotic fluid samples $(n=473)$ were obtained from 408 high-risk pregnancies at the University of Cincinnati between 
June 1986 and December 1987. Amniotic fluid was obtained by amniocentesis $(n=334)$ or vaginal collection after rupture of membranes $(n=139)$. Indications for amniocentesis were either elective delivery, premature labor, or potential blood group incompatibility. Twenty-five samples were analyzed separately because of oligohydramnios $(n=23)$ or polyhydramnios $(n=2)$ as determined by ultrasonography. Amniotic fluid was sampled within 48 h of delivery in 209 cases. Maternal and neonatal histories were determined by retrospective chart review. The prenatal use of cigarettes, alcohol, street drugs, or medications including tocolytics, theophylline, $\beta$-adrenergics, and corticosteroids was reported if it occurred during the pregnancy in question. Substance use was not further quantitated. Assignment of gestational age at the time of delivery was based on the last menstrual period, confirmed by fetal sonography and/or clinical assessment using the Ballard scale for newborn maturity (19). If the last menstrual period varied by more than $2 \mathrm{wk}$ from the Ballard rating, gestational age was assigned by physical examination. Gestational age at the time of amniotic fluid sampling was extrapolated from the gestational age at birth. Administration of exogenous surfactant was noted $(n=1)$. Appropriateness of birth weight for gestational age was determined by reference to the method of Battaglia and Lubchenco (20).

RDS was diagnosed in infants with clinical signs of respiratory distress (tachypnea greater than 60 breaths/min, grunting, or intercostal retractions) who required supplemental oxygen within $3 \mathrm{~h}$ of birth and for greater than $24 \mathrm{~h}$ and whose chest $\mathrm{x}$-rays were consistent with a diffuse reticulogranular pattern with air bronchograms $(n=30)$. Infants with $\mathrm{x}$-ray signs of pneumonia or bacteriologic evidence of sepsis and respiratory distress were analyzed separately $(n=5)$. Transient tachypnea of the newborn was diagnosed in those infants with clinical signs of respiratory distress (tachypnea greater than 60 breaths/min, grunting, or retractions) who required supplemental oxygen for less than 24 $\mathrm{h}$ after birth or whose chest $\mathrm{x}$-rays demonstrated perihilar streaking and intralobar fluid $(n=62)$. Pulmonary hypoplasia associated with congenital anomalies was diagnosed in two infants.

Phospholipid assays. The L/S and PG content were determined in the clinical laboratory immediately after fluid collection. The remainder of the sample was then stored at $-20^{\circ} \mathrm{C}$ for future analysis of surfactant protein content. The $\mathrm{L} / \mathrm{S}$ was determined by two-dimensional, thin-layer chromatography after cold acetone precipitation (8). Each sample was run in duplicate and samples with a difference in the ratio of greater than 0.2 were remeasured. L/S less than 2.0 were considered immature. PG was determined by thin-layer chromatography using dichlorofluoroscein $(0.02 \%)$ and UV light for detection (8). PG was reported as positive (mature) or negative (immature).

$S P-A$ ELISA. Amniotic fluid contents of SP-A and SP-B were determined by ELISA. SP-A was purified from surfactant obtained by lung lavage of a patient with alveolar proteinosis (21, 22). Polyclonal anti-human SP-A antibodies were prepared in goats and New Zealand rabbits by repeated injection of approximately $1 \mathrm{mg}$ purified SP-A in Freund's complete adjuvant. The antisera were specific for SP-A as assessed by immunoblot of alveolar proteinosis lavage and human amniotic fluid. The goat

Table 1. Characteristics of sampled pregnancies

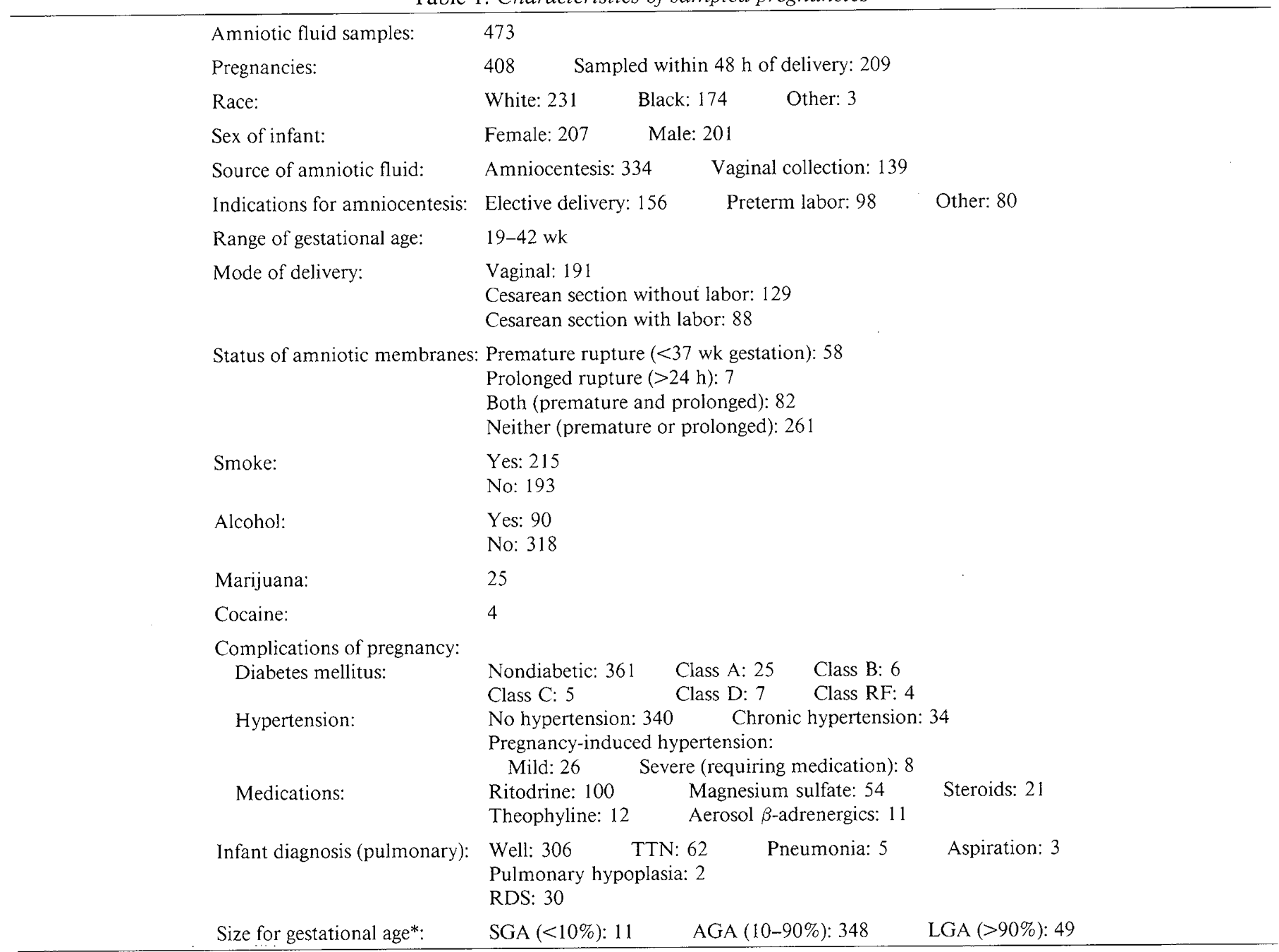

* SGA, small for gestational age: AGA, average for gestational age; LGA, large for gestational age. 


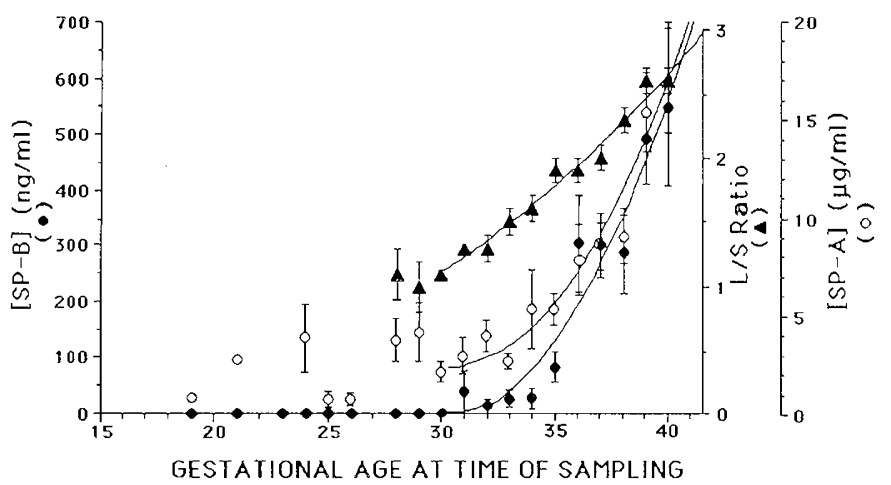

(weeks)

Fig. 1. Mean human amniotic fluid L/S, [SP-A], and [SP-B] at various gestational ages. The values are expressed as mean \pm SD. [SP-A] (open circle, $n=442$ ) and [SP-B] (closed circle, $n=443$ ) were measured by ELISA; L/S (closed triangle, $n=278$ ) was determined by thin-layer chromatography as described in Materials and Methods. Values from 14 41 - to $42-w k$ gestation pregnancies and from 33 pregnancies complicated by lung oligohydramninios ( $n=23)$, polyhydramnios $(n=2)$, or congenital anomalies $(n=8)$ were excluded. Best fit regression lines, in each case a 2 nd order polynomial, are given for amniotic fluid samples of 30 to 40 wk gestation.

and rabbit anti-SP-A antisera were used as first and second antibodies in a capture ELISA as previously described (18). Each assay plate included a standard curve generated with purified human SP-A $(5-100 \mathrm{ng} / \mathrm{mL})$ and four serial dilutions of each amniotic fluid sample adjusted to within the linear range of the assay. The SP-A ELISA was quantitated by determination of absorbance at $490 \mathrm{~nm}$.

$S P-B E L I S A$. SP-B was purified from bovine lung lavage as previously described (23). The purity and concentration of the bovine SP-B standard were confirmed by amino acid composition using reverse-phase HPLC on a Waters Pico-Tag column (Waters Associates, Millipore Corp., Milford, MA) to quantitate phenylthiocarbamyl-amino acid derivatives and by sequence analysis by Edman degradation and gas phase sequencer (2427). The homology between bovine and human SP-B is approximately $80 \%$ (28). Polyclonal anti-human SP-B antibodies were generated in New Zealand rabbits by repeated injection of a human-based synthetic SP-B polypeptide (AA 1-60) in Freund's complete adjuvant and were used to coat the ELISA plate (29). Monoclonal anti-human SP-B antiserum was prepared from ascitic fluid of nude mice injected intraperitoneally with mouse spleen-myeloma hybridomas selectively producing anti-human SP-B antibodies. The murine spleen cells were isolated by dilutional cloning from mice repeatedly immunized with human cadavar lung lavage in Freund's adjuvant. The murine anti-SP$\mathrm{B}$ antiserum was used as second antibody in the capture ELISA. The specificity of the anti-SP-B antisera was demonstrated by immunoblot of bovine serum, whole bovine surfactant, purified bovine SP-B, and human surfactant (23). Nonspecific binding was blocked with $5 \mathrm{mg} / \mathrm{mL}$ BSA and $5 \%$ human serum. Peroxidase-conjugated anti-mouse $\mathrm{IgG}$ was used to quantify the bound antibody SP-B complexes as previously described (18). Each assay plate included a standard curve generated with purified bovine SP-B $(5-100 \mathrm{ng} / \mathrm{mL})$. Four serial dilutions of each amniotic fluid sample were made in $50 \mathrm{mM}$ phosphate buffered solution with $0.5 \%$ Nonidet P-40 (Sigma Chemical Co., St. Louis, $\mathrm{MO}$ ) and were adjusted to within the linear range of assay. The SP-B ELISA was quantitated by determination of absorbance at $490 \mathrm{~nm}$. Analysis of the ELISA was performed on an Apple IIE computer in line with a Dynatech (Chantilley, VA) microtiter plate reader.

Data were expressed as mean $\pm \mathrm{SD}$ unless otherwise indicated. Associations of the [SP-A], [SP-B], L/S, and PG content with the occurrence of neonatal RDS were determined by contingency
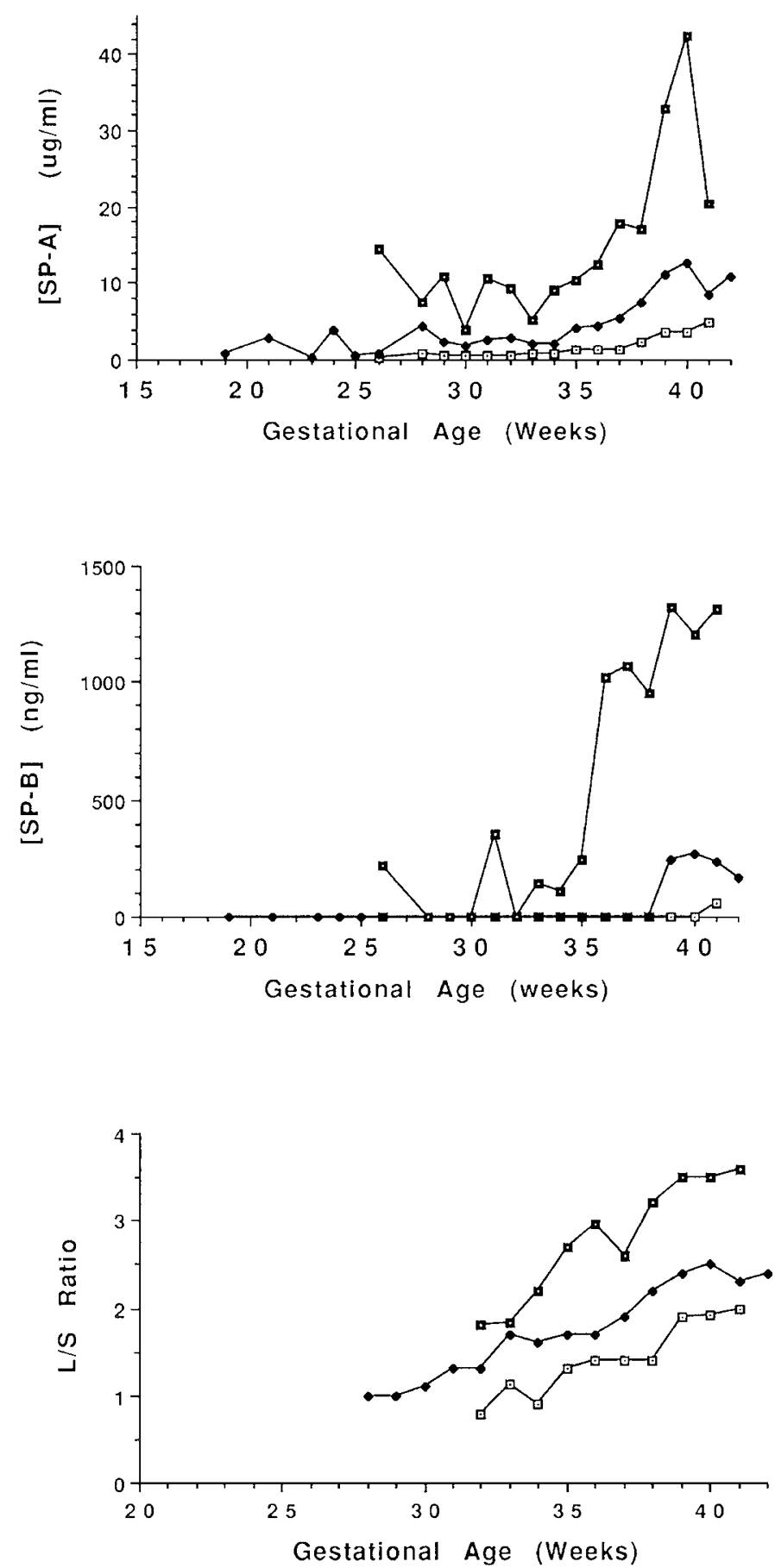

Fig. 2. Tenth (open square), 50th (black diamond), and 90th (closed square) percentile values of human amniotic fluid [SP-A] $(n=442)$, [SP$\mathrm{B}](n=443)$, and $\mathrm{L} / \mathrm{S}(n=278)$ at various gestational ages. Values from 33 pregnancies complicated by oligohydramnios $(n=23)$, polyhydramnios $(n=2)$, or congenital anomalies $(n=8)$ were excluded from the analysis. [SP-A] and [SPA-B] were measured by ELISA; L/S was determined by thin-layer chromatography as described in Materials and Methods.

table analysis. [SP-A] $<1 \mu \mathrm{g} / \mathrm{mL},[S P-B]=0 \mathrm{ng} / \mathrm{mL}, \mathrm{L} / \mathrm{S}<2.0$, and negative $\mathrm{PG}$ were selected as cutoff values indicating fetal pulmonary immaturity (positive test). The effects of potentially confounding variables including infant sex, size for gestational age, race, Apgar scores, prolonged or premature rupture of membranes, maternal diabetes, hypertension, smoking, use of ethanol, and medications were screened by Mann Whitney U or Kruskal-Wallis nonparametric tests. Variables significantly as- 
Table 2. Aberrant surfactant indices detected in amniotic fluids sampled from pregnancies complicated by oligohydramnios, polyhydramnios or congenital abnormalities*

\begin{tabular}{|c|c|c|c|}
\hline Amniotic fluid status & $\begin{array}{l}\text { Gestational } \\
\text { age (wk) }\end{array}$ & Associated anomaly & Test abnormality \\
\hline \multirow[t]{10}{*}{ Oligohydramnios } & 30 & $\begin{array}{l}\text { Pulmonary hypoplasia } \\
\text { Hydronephrosis }\end{array}$ & {$[\mathrm{SP}-\mathrm{A}]>90 \%$} \\
\hline & 36 & $\begin{array}{l}\text { Trisomy } 21 \\
\text { Congenital heart disease }\end{array}$ & {$[\mathrm{SP}-\mathrm{A}]>90 \%$} \\
\hline & 36 & $\begin{array}{l}\text { Maternal SLE } \\
\text { Fetal heart block }\end{array}$ & $\mathrm{L} / \mathrm{S}>90 \%$ \\
\hline & 40 & Unknown etiology & {$[\mathrm{SP}-\mathrm{B}]>90 \%$} \\
\hline & 37 & $\begin{array}{l}\text { Unknown etiology } \\
\text { Villamentous cord insertion }\end{array}$ & {$[\mathrm{SP}-\mathrm{B}]$ and $\mathrm{L} / \mathrm{S}>90 \%$} \\
\hline & 39 & Unknown etiology & {$[\mathrm{SP}-\mathrm{A}],[\mathrm{SP}-\mathrm{B}]$, and $\mathrm{L} / \mathrm{S}>90 \%$} \\
\hline & 38 & $\begin{array}{l}\text { IUGR by US, not by clinical } \\
\text { exam }\end{array}$ & {$[\mathrm{SP}-\mathrm{A}]$ and $[\mathrm{SP}-\mathrm{B}]>90 \%$} \\
\hline & 36 & IUGR, unknown etiology & {$[\mathrm{SP}-\mathrm{B}]>90 \%$} \\
\hline & 39 & Unknown etiology & $\mathrm{L} / \mathrm{S}>90 \%$ \\
\hline & 31 & $\begin{array}{l}\text { Pulmonary hypoplasia } \\
\text { Dysplastic kidneys } \\
\text { Congenital heart disease }\end{array}$ & {$[\mathrm{SP}-\mathrm{A}]$ and $[\mathrm{SP}-\mathrm{B}]>90 \%$} \\
\hline Polyhydramnios & 33 & $\begin{array}{l}\text { Severe polyhydramnios } \\
\text { Hydrocephalus }\end{array}$ & {$[\mathrm{SP}-\mathrm{A}]$ and $\mathrm{L} / \mathrm{S}<10 \%$} \\
\hline \multirow[t]{2}{*}{ Normal amniotic fluid } & 36 & $\begin{array}{l}\text { + Cytomegalovirus culture } \\
\text { Microcephaly } \\
\text { Hydrocephalus, ex vacuo }\end{array}$ & {$[\mathrm{SP}-\mathrm{A}]>90 \%$} \\
\hline & 39 & Osteogenesis imperfecta & {$[\mathrm{SP}-\mathrm{A}]$ and $\mathrm{L} / \mathrm{S}<10 \%$} \\
\hline
\end{tabular}

* SLE, systemic lupus erythematous; US, ultrasound; IUGR, intrauterine growth retardation.

sociated with amniotic fluid concentrations of SP-A or SP-B univariately were included in multiple regression analyses. Because of SP-A and SP-B not being normally distributed within each gestational age grouping and because of the polynomic rise in the surfactant indices with advancing gestation, the multiple regression analyses were performed using the logarithmic transformation of SP-A, SP-B, and L/S ratio and including (gestational age $)^{2}$ and (gestational age) as independent variables. Statistical significance was defined as $p<0.05$ unless otherwise specified. All statistical analyses were performed using Statview $512^{+}$software (Brainpower, Inc., Agoura Hill, CA).

\section{RESULTS}

Surfactant protein immunoassays. Characteristics of the antisera used in the SP-A ELISA have been previously reported (18). The polyclonal rabbit anti-human SP-B antiserum and the monoclonal mouse anti-human SP-B antibody were highly reactive with the mature, $\mathrm{M}_{\mathrm{r}}=8700 \mathrm{SP}-\mathrm{B}$ protein as determined by single-phase ELISA and immunoblot of either purified bovine SP-B or whole bovine surfactant after separation by SDS-PAGE. The reproducibility and precision of the SP-B ELISA, assessed as interassay and intraassay coefficients of variation, were within $25 \%$. Correlation coefficients of the standard curves were generally $0.95-0.99$. The limit of detection was reliably $25 \mathrm{ng} / \mathrm{mL}$, and the sensitivity (change in absorbance per change in [SP-B]) was approximately 0.003 . SP-A and SP-B were stable in aliquots of an amniotic fluid sample assayed over a 6-mo period of storage at $-20^{\circ} \mathrm{C}$. SP-B was $100 \%$ recoverable by the ELISA from amniotic fluid spiked with standard SP-B within the range of concentrations detected in the current study samples. Addition of 2 to $50 \%$ (vol/vol) EDTA-anticoagulated whole human blood or meconium to standard concentrations of SP-A and SP-B did not significantly alter the ELISA of SP-A or SP-B. Meconium did not react with the ELISA of either SP-A or SP-B. Addition of $2-30 \%$ blood or $10 \%$ meconium to amniotic fluid samples decreased (3-20\%) the concentrations of SP-A and SP-B compared with noncontaminated samples.

Ontogeny of $L / S, S P-A$, and $S P-B$. Characteristics of the pregnancies included in this study are presented in Table 1.
Gestational age at the time of amniotic fluid sampling was 19 to 42 wk ( $n=1-67$ samples per gestational week). RDS was diagnosed in 30 infants (19 Caucasian, 11 black; 14 male, 16 female) with a mean gestational age of $30.7 \pm 4.2$ wk (mean \pm SD). Transient tachypnea of the newborn was diagnosed in 62 infants. Pneumonia or sepsis was detected in five infants. Amniotic fluid aspiration and meconium aspiration were diagnosed in two infants and one infant, respectively. Exogenous surfactant was administered only for treatment of established RDS (i.e. rescue protocol) and did not alter the assessment of respiratory disease. No pulmonary disease was detected in 306 neonates. Mean gestational age of those without RDS was $36.3 \pm 3.0 \mathrm{wk}$ (mean $\pm \mathrm{SD}$ )

Amniotic fluid concentration of SP-A and SP-B and the L/S increased with advancing gestation (Fig. 1). SP-A was detected in the single amniotic fluid samples obtained at 19,21, and 23 wk. A gradual increase in mean [SP-A] occurred over the next 7 wk, followed by a quadratic increase between 30 and $40 \mathrm{wk}$ gestation $\left(R^{2}=0.96\right)$. The increase in L/S after approximately 30 wk gestation was also best described by a quadratic equation $\left(R^{2}=0.98\right)$. SP-B was first detectable in amniotic fluid at $31 \mathrm{wk}$ gestation. Thereafter, mean [SP-B] increased in a quadratic fashion to term $\left(R^{2}=0.94\right)$. When considered by gestational week, the mean [SP-A] and [SP-B] values correlated with each other and with the mean $\mathrm{L} / \mathrm{S}\left(R^{2}=0.83\right.$, [SP-A] versus $[\mathrm{SP}-\mathrm{B}] ; R^{2}=$ 0.74 , [SP-A] versus $\mathrm{L} / \mathrm{S} ; R^{2}=0.64$, [SP-B] versus $\mathrm{L} / \mathrm{S}, 28-42 \mathrm{wk}$ gestation). Correlation of the raw data for [SP-A] and [SP-B] with $\mathrm{L} / \mathrm{S}\left(R^{2}=0.26\right.$ and 0.23 , respectively) reflected the wide variability in amniotic fluid content of SP-A, SP-B, and L/S within each week of gestation. The concentrations of SP-A and SP-B were not normally distributed within each week of gestation. The median, 10th, and 90th percentiles of [SP-A] and [SPB] are represented in Fig. 2.

Amniotic fluid samples obtained from 33 pregnancies complicated by an abnormal quantity of amniotic fluid and/or congenital anomalies are not included in Figure 2. Twenty-five of these pregnancies were complicated by oligohydramnios $(n=23)$ or polyhydramnios $(n=2)$ as determined by ultrasonography. Congenital anomalies or intrauterine growth retardation were associated with oligohydramnios or polyhydramnios in 11 cases. 
a.

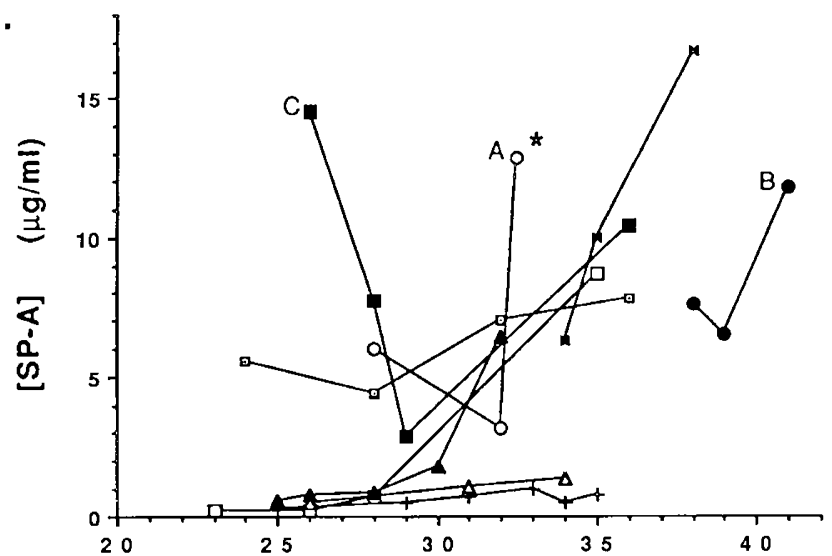

b.

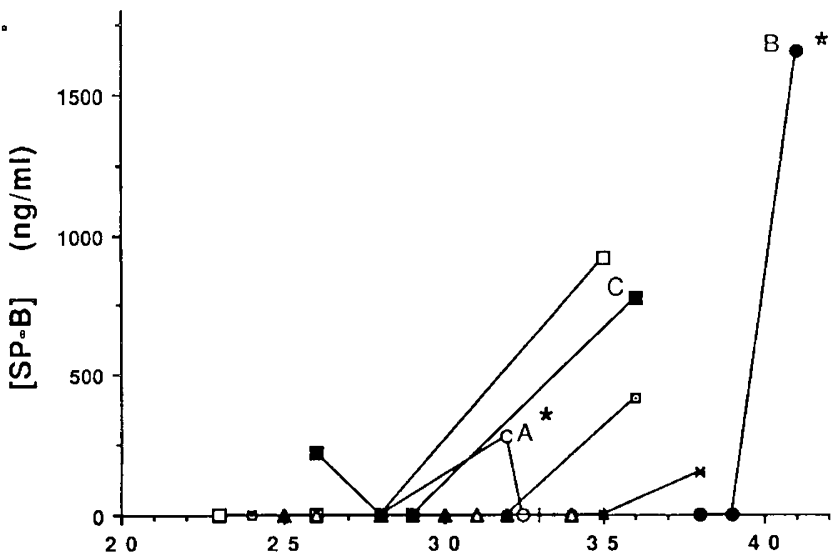

C.

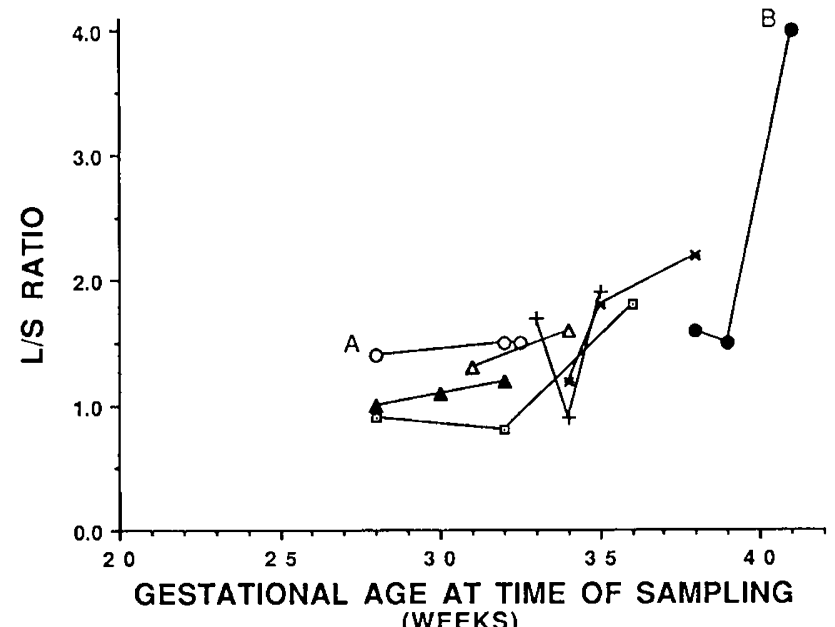

Fig. 3. Representative data of amniotic fluid [SP-A], [SP-B], and L/ $\mathrm{S}$ from pregnancies sampled on more than one occasion. Each of the nine symbols (consistent between panels $a, b$, and $c$ ) represents an individual pregnancy sampled on three or more occasions. Open circles, closed circles, and closed squares represent patients $A, B$, and $C$, respectively, as referred to in the text. The surfactant proteins and phospholipids were measured as described in Materials and Methods. Asterisks highlight three indices that were greater than the 90th percentile for gestational age as defined in Figure 2.

An additional eight neonates had congenital anomalies but normal amniotic fluid volume. [SP-A], [SP-B], or L/S were outside of the 10th or 90 th percentiles for gestational age (Fig. 2) in 13 of the 33 amniotic fluid samples obtained from pregnancies complicated by the abnormal quantity of amniotic fluid or by congenital anomalies, as shown in Table 2. The SP-A and SP-B content and $\mathrm{L} / \mathrm{S}$ of the remaining 20 pregnancies associated with congenital anomalies or abnormal amniotic fluid volume were within the 10th to 90th percentiles defined in Figure 2, including three infants with mild to severe hydronephrosis (one with oligohydramnios, two with normal fluid), three diagnosed to have intrauterine growth retardation and oligohydramnios, seven with oligohydramnios of unknown etiology, and one infant each with 1) oligohydramnios and Conradii Syndrome, 2) polyhydramnios, hydrocephalus, imperforate anus, and hydronephrosis, 3) Trisomy 21, 4) Arnold-Chiari malformation, 5) congenital heart disease, 6) maternal hyperthyroidism, and 7) nephroblastoma. Four infants with intrauterine growth retardation and normal amniotic fluid volumes had amniotic fluid indices within expected limits.

Amniotic fluid was sampled from 46 pregnancies by amniocentesis on more than one occasion, generally because of blood group antigen incompatibility. Representative data, composed of those patients who were sampled three or more times, are presented in Figure 3. For each patient, the L/S, the detectability of PG, and the concentrations of SP-A and SP-B generally increased with advancing gestation. Patient A (open circles) received betamethasone, ritodrine, and magnesium sulfate $4 \mathrm{~d}$ before her second sample, which showed a transient decrease in [SP-A] and a rise in SP-B. Patient B (closed circles) received brethine and ritodrine $5 \mathrm{wk}$ before the first amniocentesis. She was treated with tocolytics and two doses of betamethasone $8 \mathrm{~d}$ before the second amniotic fluid sampling. Patient $\mathrm{C}$ (closed squares) received several antibodies between 30 and $36 \mathrm{wk}$ gestation. No medications were reported in the other pregnancies represented in Figure 3. There was considerable variability with regard to peak [SP-A] and [SP-B] detected at term gestation.

Prediction of fetal lung maturity. Amniotic fluid samples were obtained from 209 pregnancies within $48 \mathrm{~h}$ of delivery. The values of [SP-A], [SP-B], L/S, and PG obtained from these 209 samples were tested by contingency table analysis to determine the correlation with the development of neonatal RDS. Specificity, sensitivity, accuracy, and positive and negative predictive values calculated on the 209 samples are represented in Table 3.

As shown in Table 3, SP-A was a more specific test for RDS than was the $\mathrm{L} / \mathrm{S} ; 93.0 \%$ of the infants who did not develop RDS had mature [SP-A] $(\geq 1 \mu \mathrm{g} / \mathrm{mL})$ compared with $86.7 \%$ with $\mathrm{L} / \mathrm{S}$ $\geq 2.0$. However, only $26.3 \%$ of the infants who developed RDS would have been detected by [SP-A] $<1 \mu \mathrm{g} / \mathrm{mL}$ compared with $82.3 \%$ correctly detected by $\mathrm{L} / \mathrm{S}$ ratio $<2.0$, i.e. the sensitivity of the amniotic fluid [SP-A] $<1$ was poor. The sensitivity of the SP-A concentration for RDS was improved by increasing the cutoff value (i.e. [SP-A] $<3$ ) but the specificity and accuracy decreased. The sensitivity of $[\mathrm{SP}-\mathrm{B}]=0$ to predict RDS was comparable to that for L/S (82.4 versus $82.3 \%$ ); however, [SP$\mathrm{B}]=0$ was less specific, incorrectly predicting $47.3 \%$ of healthy neonates to develop RDS versus $13.3 \%$ by $\mathrm{L} / \mathrm{S}$. The greatest sensitivity and specificity were attained with the commonly used combination of $\mathrm{L} / \mathrm{S}<2.0$ and negative $\mathrm{PG}$, which correctly predicted $100 \%$ of the infants who developed RDS and $94.2 \%$ of those who did not develop RDS. Other combinations of the four amniotic fluid indices did not improve both the sensitivity and specificity or overall accuracy of the test. The positive predictive value reflects the likelihood that a positive test, suggesting pulmonary immaturity, will correctly identify an infant who will develop RDS. The positive predictive value of $\mathrm{L} / \mathrm{S}<$ 2.0 and negative $\mathrm{PG}$ was only $45.5 \%$, yet it was not improved by consideration of the [SP-A] and [SP-B]. When only the 106 samples for which all four amniotic fluid indices were available were considered, the contingency table analysis was somewhat altered (data not shown). However, the relative probability values of the tests, relative to each other, were unchanged. The accuracy and positive predictive value of the amniotic fluid indices were greatly improved when all four values reflected immaturity, i.e. $\mathrm{L} / \mathrm{S}<2$, negative $\mathrm{PG},[\mathrm{SP}-\mathrm{A}]<1$, and $[\mathrm{SP}-\mathrm{B}]=0$. However, the sensitivity for RDS, when all four tests reflected immaturity, 
Table 3. Association of [SP-A], [SP-B], L/S, and PG content with the development of neonatal RDS*

\begin{tabular}{|c|c|c|c|c|c|}
\hline Positive test & Sensitivity (\%) & Specificity $(\%)$ & Accuracy $(\%)$ & $+\mathrm{PV}(\%)$ & $-\mathrm{PV}(\%)$ \\
\hline$[\mathrm{SP}-\mathrm{A}]<1$ & 26.3 & 93.0 & 86.8 & 27.8 & 92.5 \\
\hline$[\mathrm{SP}-\mathrm{A}]<3$ & 64.7 & 77.1 & 76.0 & 20.4 & 96.0 \\
\hline$[S P-B]=0$ & 82.4 & 52.7 & 55.3 & 14.0 & 97.0 \\
\hline $\mathrm{L} / \mathrm{S}<2$ & 82.3 & 86.7 & 86.5 & 26.3 & 98.9 \\
\hline$[\mathrm{SP}-\mathrm{A}]<1$ and/or $[\mathrm{SP}-\mathrm{B}]=0$ & 82.4 & 51.7 & 54.3 & 13.1 & 96.9 \\
\hline $\mathrm{L} / \mathrm{S}<2, \mathrm{SP}-\mathrm{A}<1$, and/or $[\mathrm{SP}-\mathrm{B}]=0$ & 60.0 & 90.4 & 89.0 & 23.1 & 97.9 \\
\hline$[\mathrm{SP}-\mathrm{A}]<1$ or $\mathrm{L} / \mathrm{S}<2$ & 83.3 & 84.8 & 84.7 & 23.8 & 98.9 \\
\hline$[\mathrm{SP}-\mathrm{B}]=0$ or $\mathrm{L} / \mathrm{S}<2$ & 100 & 57.7 & 59.6 & 10.2 & 100 \\
\hline$P G$ negative & 73.3 & 85.9 & 84.9 & 30.6 & 97.4 \\
\hline $\mathrm{L} / \mathrm{S}<2$ and $\mathrm{PG}$ negative & 100 & 94.2 & 94.4 & 45.5 & 100 \\
\hline $\begin{array}{l}\mathrm{L} / \mathrm{S}<2, \mathrm{PG} \text { negative, }[\mathrm{SP}-\mathrm{B}]=0 \text {, and } \\
\quad[\mathrm{SP}-\mathrm{A}]<1\end{array}$ & 25 & 100 & 97.2 & 100 & 97.1 \\
\hline
\end{tabular}

\footnotetext{
* Sensitivity, frequency of positive test results in those with RDS [true-positive $\div$ (true-positive + false-negative results)]; specificity, frequency of negative test results in those without RDS [true-negative $\div$ (true-negative + false-positive results)]; accuracy, proportion of test results that correctly predict outcome $[$ (true-positive + true-negative) $\div$ total number of tests]; +PV (+predictive value), frequency of RDS in those with positive test results: and $-\mathrm{PV}$ (-predictive value), frequency of no RDS in those with negative test results.
}

was greatly reduced; only $25 \%$ of the infants who would develop RDS were identified.

[SP-A], [SP-B], and L/S were not significantly affected by infant sex, Apgar score, prolonged or premature rupture of the membranes, size for gestational age, maternal diabetes, hypertension, use of ethanol, theophylline, ritodrine, magnesium sulfate, corticosteroids, or insulin when analyzed by multiple regression analyses with gestational age as an independent variable. Overall, [SP-A], [SP-B], and L/S values obtained by amniocentesis were statistically greater than those obtained by vaginal collection. However, when source of amniotic fluid and gestational age were included as independent variables in multiple regression analyses, the sample source was not significant and did not contribute to the variability in the data. When amniocentesis and vaginal pool samples were spiked with known quantities of SP-B, the recoverability was comparable. Amniotic fluid samples were obtained in six cases within $7 \mathrm{~d}$ after prenatal corticosteroid treatment and from three cases receiving chronic corticosteroids. The amniotic fluid indices of these nine steroid-exposed cases were not significantly different from those of the nonsteroid treated pregnancies. [SP-A], [SP-B], and L/S were significantly greater in amniotic fluid of black infants than of Caucasian infants despite statistically considering the gestational age at sampling, maternal hypertension, medications, or size of the infant (Fig. $4 A$ ). Maternal nutrition and prepregnancy weight were not considered in the current study. Amniotic fluid [SP-A] was significantly higher in amniotic fluid obtained from mothers who smoked cigarettes compared with that obtained from mothers who did not smoke (Fig. $4 B$ ). SP-B and L/S were not significantly affected by maternal smoking habits.

\section{DISCUSSION}

Human amniotic fluid concentration of SP-A and the L/S increased with advancing gestational age as previously reported (11, 13-18). The correlation of the $\mathrm{L} / \mathrm{S}, \mathrm{PG}$, and [SP-A] with gestational age and fetal lung maturity reported in the present study was comparable to that described in the literature $(8,9$, 14,30 ). In addition, SP-B was detected in human amniotic fluid by ELISA. Like [SP-A] and L/S, amniotic fluid concentration of SP-B increased during the $3 \mathrm{rd}$ trimester of pregnancy. Amniotic fluid concentrations of SP-A and SP-B correlated with fetal lung maturity as assessed by the presence of RDS in the neonate. The predictive value of the amniotic fluid $\mathrm{L} / \mathrm{S}$ and $\mathrm{PG}$ content for RDS was not improved by consideration of the surfactantspecific proteins SP-A and SP-B.

King et al. (17), in 1975, determined amniotic fluid content of surfactant apoproteins by latex agglutination assay, likely primarily detecting SP-A. The apoproteins were detectable as early as 29 wk gestation and increased with advancing gestation, in association with increasing content of surfactant phospholipids. Similar ontogenic changes in SP-A and L/S were reported in amniotic fluid and in fetal rat lung (5-16). The results of the current study, presented in Figure 1, are consistent with detection of human fetal SP-A mRNA. Levels of SP-A mRNA were low or undetectable in 13- to 25-wk gestation human fetal lung explants before culture $(31,32)$. SP-A mRNA was first detected by in situ hybridization in human fetal lung at $16 \mathrm{wk}$ gestation (33). The normative percentiles for [SP-A] and L/S presented in Figure 2 of the current study agree closely with the results of Hallman et al. (14) and Gluck et al. (8), respectively.

The ontogeny of SP-B in human pregnancy has not been previously reported. In the present study, ontogeny of SP-B in human amniotic fluid was similar but not identical to that previously demonstrated for amniotic fluid SP-A and L/S. SP-B was first detected and increased sharply after $32 \mathrm{wk}$ gestation, several weeks after SP-A. In the present study, the surge in amniotic fluid SP-A appeared slightly later than the increase in $\mathrm{L} / \mathrm{S}$. Thus, the developmental appearance of SP-A and lecithin could be readily distinguished. Slavkin et al. (34) observed the appearance of lamellar bodies before detection of SP-A expression, suggesting that the surfactant apoproteins are regulated independently of the surfactant phospholipids and are not necessary for early lamellar body formation. Differences in timing of expression of SP-A and SP-B support the concept that the proteins are also independently regulated.

The L/S and the presence of PG in amniotic fluid are used routinely to estimate fetal lung maturity to optimize the management of high-risk pregnancies. A significant false-positive and false-negative rate occurs in $\mathrm{L} / \mathrm{S}$ and $\mathrm{PG}$ testing as applied to the prediction of fetal lung maturity. Considerable variation exists in the timing of the L/S surge, especially between 33 and $37 \mathrm{wk}$ of gestation. Many fetuses with L/S in the "transitional zone" (1.5-1.9) are falsely predicted to be at risk for RDS. In the current study, the frequency of RDS in neonates whose amniotic fluid L/S and PG content predicted fetal lung immaturity was only $45.5 \%$, a positive predictive value consistent with previously published data $(9,11)$. The delivery of infants incorrectly predicted to be immature may be delayed, with potential detriment to mother and fetus. Infants with falsely immature $\mathrm{L} / \mathrm{S}$ and $\mathrm{PG}$ assays may be needlessly subjected to surfactant replacement, a therapy that is showing promise for preventing or reducing the severity of RDS in prematurely born infants. Hallman et al. (14) reported enhanced accuracy of prediction of RDS when amniotic fluid [SP-A] was considered along with transitional zone values of $\mathrm{L} / \mathrm{S}$. However, the assessment of amniotic SP-A and SP-B in the current study did not improve the positive predictive value of the amniotic fluid tests.

The L/S may falsely predict fetal lung maturity, particularly in diabetic patients (35-37). Evaluation of $P G$ in conjunction 
A.
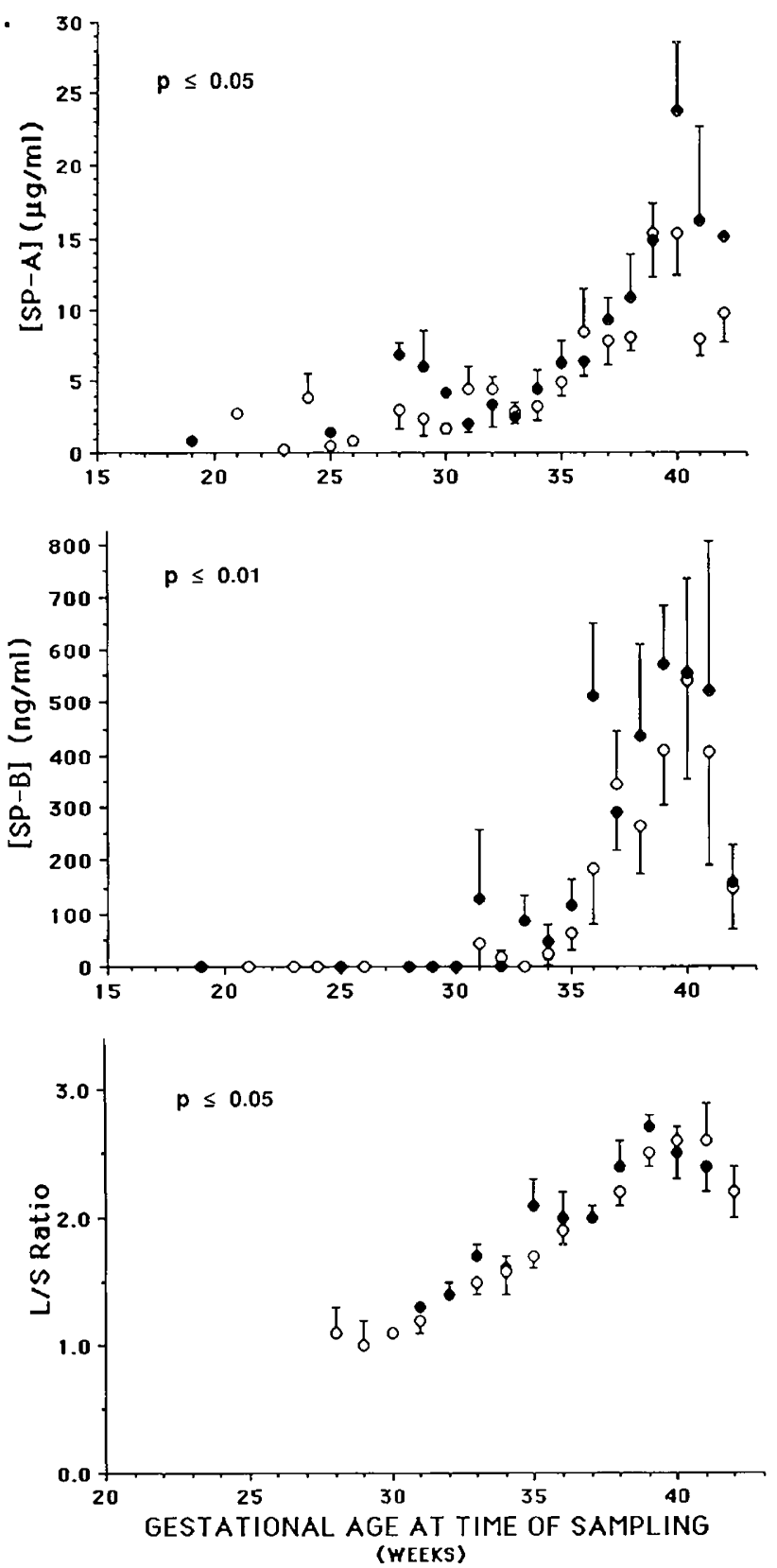

B.
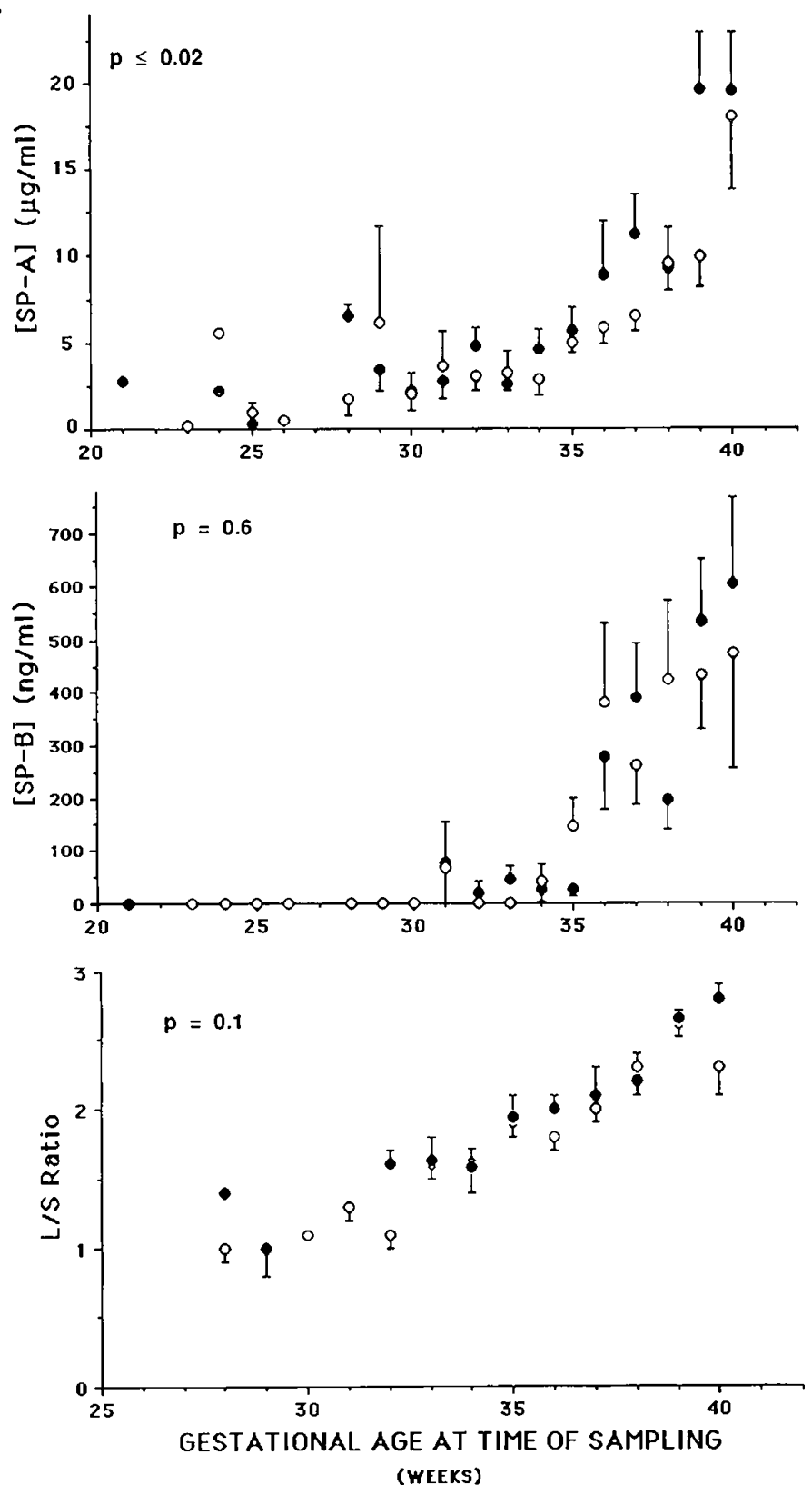

Fig. 4. Amniotic fluid indices stratified by race $(A)$ (black, $n=174$, closed circles; Caucasian, $n=231$, open circles) and maternal smoking habit $(B)$ (positive smoking history, $n=215$, closed circles; negative smoking history, $n=193$, open circles). The values are expressed as mean \pm SEM. Where standard error bars are not present, $n=1$. Values from 33 pregnancies complicated by hydramnios or congenital anomalies were excluded. The $p$ values represent the result of multiple regression analysis including (gestational age) ${ }^{2}$, gestational age, and either race or maternal smoking habit as independent variables and using the logarithmic transformation of the surfactant indices.

with the L/S has been used to improve the estimate of fetal lung maturity in diabetic pregnancies. Katyal et al. (37) reported that measurement of surfactant apoproteins by ELISA yielded a better estimate of fetal lung maturity in diabetic patients than did the $\mathrm{L} / \mathrm{S}$. McMahan et al. (18) reported no difference in SP-A concentration in amniotic fluids of diabetic patients compared with controls pair-matched for gestational age. Hallman et al. (38) also reported no difference in SP-A content between diabetic and control amniotic fluid. In the current study, there was no difference in SP-A and SP-B content or L/S detected at given gestational ages in diabetic versus nondiabetic pregnancies. Current aggressive management of maternal diabetes may result in normal fetal pulmonary maturation (39).

When the data of the current study are analyzed as a whole, the amniotic fluid [SP-A], [SP-B], and L/S were not significantly affected by maternal exposure to medications including cortico- steroids or tocolytics. It is interesting that patients A and B in Figure 3 both demonstrated a transient decrease and then increase in [SP-A] and an increase in [SP-B] in amniotic fluid sampled after receiving betamethasone and tocolytics. The data of the present study, however, are insufficient to support an association between maternal corticosteroid therapy and human amniotic fluid or fetal lung surfactant proteins.

The concentrations of SP-A and SP-B were altered in some cases of abnormal amniotic fluid volume or congenital anomaly. Pulmonary maturation may be altered in the fetus with anomalies due to either abnormal volume or composition of the amniotic fluid or secondary to the underlying congenital anomaly itself. In the present study, increased surfactant protein and phospholipid were noted in the presence of oligohydramnios and in the presence of cytomeglovirus infection; decreased surfactant proteins and phospholipids were noted in a single case of poly- 
hydramnios and in the presence of osteogenesis imperfecta. It is likely that the changes in [SP-A], [SP-B], and L/S noted in pregnancies complicated by oligohydramnios or polyhydramnios reflect dilution effects or may simply be outliers of the normal curve. The $\mathrm{L} / \mathrm{S}$, with sphingomyelin as an internal control for volume, was unexpectedly altered in five of the patients with abnormal amniotic fluid or congenital anomaly. In the current study, there is not sufficient data to support an association between abnormal amniotic fluid volume or congenital anomaly and altered surfactant indices or fetal lung development.

Amniotic fluid SP-B was not detected in a large number of infants who had no evidence of respiratory distress. Although RDS rarely occurred if SP-B was detectable, SP-B was not detected in many infants with apparently mature lungs. SP-B mRNA has been detected in human fetal lung at $13 \mathrm{wk}$ gestation and rises to $50 \%$ of adult level at $24 \mathrm{wk}$ gestation (40). Significant variability in SP-B mRNA was noted in fetal human lungs from 22-24 wk (41). Several factors may account for the discrepancy in expression of SP-B mRNA in the fetal lung and detection of the SP-B peptide in amniotic fluid. The mature SP-B peptide is produced by proteolysis of a larger precursor protein that is not detected by the SP-B ELISA. It is possible that SP-B is expressed at earlier stages of development but that the active SP-B peptide is either not secreted or not proteolytically processed. Alternatively, SP-B from the fetal lung may be rapidly metabolized from the amniotic fluid. It is possible that normal lung function requires levels of SP-B production below that detected by the SP-B ELISA or that SP-B secretion is enhanced in the process of delivery. It is unlikely that amniotic fluid substances interfere with the SP-B ELISA. Known quantities of SP-B added to amniotic fluid samples were recovered in the ELISA.

[SP-A] was significantly elevated in amniotic fluid from mothers who smoked during pregnancy. [SP-B] and the L/S were not affected by maternal smoking. The mechanisms and significance of this finding have not been discussed. Alterations in uteroplacental blood flow and relative fetal hypoxia due to vasoconstrictive effects of nicotine and fetal accumulation of carboxyhemoglobin may result in advanced lung maturation in fetuses whose mothers smoke $(42,43)$. The elevation of SP-A in the amniotic fluid of mothers who smoked during pregnancy may be a fetal stress response to chronic hypoxia.

In the current study, [SP-A], [SP-B], and L/S were significantly greater in the amniotic fluid of black women than in that of Caucasian women, despite consideration of gestational age and other complications of pregnancy. Fadel et al. (44) found no difference in amniotic fluid lecithin between white and black fetuses. However, black infants have a lower incidence of RDS than white infants when rate of prematurity is taken into consideration $(43,45-47)$. The elevated amniotic fluid surfactant proteins and phospholipids reported in the current study are consistent with the apparent advanced pulmonary maturation in black infants. Further study is needed to determine if enhanced lung maturity in black infants is due to genetic differences between races or to confounding factors such as maternal nutrition that are influenced by race.

In summary, the present study demonstrates that amniotic fluid SP-B, like L/S and SP-A, increases during the last trimester of gestation and may be used to predict pulmonary outcome at birth. Measurement of SP-A and SP-B do not further enhance the specificity or sensitivity of predicting RDS conferred by L/S and PG. Surfactant protein SP-A and SP-B determinations alone do not provide the accuracy of the commonly used indices of pulmonary maturity, namely $\mathrm{L} / \mathrm{S}$ and the presence or absence of PG. Differences in amniotic fluid content of SP-A in mothers who smoked and of SP-A and SP-B in black versus Caucasian women suggest possible differences in fetal pulmonary development warranting further investigation.

Acknowledgment. The authors thank Bonny L. Specker, Ph.D., for help with the statistical analysis.

\section{REFERENCES}

1. Avery ME. Mead J 1959 Surface properties in relation to atelectasis and hyaline membrane disease. Am J Dis Child 97:517-523

2. Notter RH 1988 Biophysical behavior of lung surfactant: implications for respiratory physiology and pathophysiology. Semin Perinatol 12:180-212

3. Weaver TE, Whitsett JA 1988 Structure and function of pulmonary surfactant proteins. Semin Perinatol 12:213-220

4. Weaver TE 1988 Pulmonary surfactant-associated proteins. Gen Pharmacol 19:361-368

5. Schellhase DE, Emrie PA, Fisher JA, Shannon JM 1989 Ontogeny of surfactant apoproteins in the rat. Pediatr Res 26:167-174

6. Katyal SL, Singh G 1983 An enzyme-linked immunoassay of surfactant apoproteins. Its application to the study of fetal lung development in the rat. Pediatr Res 17:439-443

7. Farrell PM, Bourbon JR, Notter RH, Marin L, Nogee LM, Whitsett JA 1990 Relationships among surfactant fraction lipids, proteins and biophysical properties in the developing rat lung. Biochim Biophys Acta 1044:84-90

8. Gluck L, Kulovich MV, Borer RC. Brenner PH, Anderson GG, Spellacy WM 1971 Diagnosis of the respiratory distress syndrome by amniocentesis. Am J Obstet Gynecol 109:440-445

9. Donald IR, Freeman RK, Goebelsmann U, Chan WH, Nakamura RM 1973 Clinical experience with the amniotic fluid lecithin/sphingomyelin ratio. I. Antenatal prediction of pulmonary maturity. Am J Obstet Gynecol 1 15:547552

10. Biezenski JJ, Pomerance W, Goodman J 1968 Studies on the origin of amniotic fluid lipid. I. Normal composition. Am J Obstet Gynecol 102:853-861

11. Kulovich MV, Hallman MB, Gluck L 1979 The lung profile. I. Normal pregnancy. Am J Obstet Gynecol 135:57-63

12. Hallman M, Kulovich M. Kirkpatrick E, Sugarman RG, Gluck L 1976 Phosphatidylinositol and phosphatidylglycerol in amniotic fluid: indices of lung maturity. Am J Obstet Gynecol 125:613-617

13. Torday JS, Nielson HC 1981 Surfactant phospholipid ontogeny in fetal rabbit lung lavage and amniotic fluid. Biol Neonate 39:266-271

14. Hallman M, Arjomaa P, Mizumoto M, Akino T 1988 Surfactant proteins in the diagnosis of fetal lung maturity. I. Predictive accuracy of the $35 \mathrm{kD}$ protein, the lecithin/sphingomyelin ratio, and phosphatidylglycerol. Am J Obstet Gynecol 158:531-535

15. Paciga JE, Shelly SA, Paterson JE, Knuppel RA, Scerbo JC, Balis JU 1988 Lung surfactant-associated glycoproteins and proteolipids in human amniotic fluids evaluated by dot immunoblotting assays. Ann Clin Lab Sci 18:141-147

16. Shelley SA, Balis JU, Paciga JE, Knuppel RA, Ruffolo EH, Bouis Jr PJ 1982 Surfactant "apoproteins" in human amniotic fluid: an enzyme-linked immunosorbent assay for the prenatal assessment of lung maturity. Am J Obstet Gynecol 144:224-228

17. King RJ, Ruch J, Gikas EG, Platzker ACG, Creasy RK 1975 Appearance of apoproteins of pulmonary surfactant in human amniotic fluid. J Appl Physiol 39:735-741

18. McMahan MJ, Mimouni F, Miodovnik M, Hull WJ, Whitsett JA 1987 Surfactant associated protein (SAP-35) in amniotic fluid from diabetic and non-diabetic pregnancies. Obstet Gynecol 70:94-98

19. Ballard JL, Novak KK. Driver M 1979 A simplified score for assessment of fetal maturation of newly born infants. J Pediatr 95:769-774

20. Battaglia FC. Lubchenco LO 1967 A practical classification of newborn infants by weight and gestational age. J Pediatr 71:159-163

21. Ross GF, Notter RH, Meuth J, Whitsett JA 1986 Phospholipid binding and biophysical activity of pulmonary surfactant-associated protein (SAP-35) and its non-collagenous COOH-terminal domain. J Biol Chem 261:1428314291

22. Ross GF. Ohning BL. Tannenbaum D, Whitsett JA 1987 Structural relationships of the major glycoproteins from human alveolar proteinosis surfactant. Biochim Biophys Acta 911:294-305

23. Whitsett JA, Hull WM, Ohning B, Ross G, Weaver TE 1986 Immunologic identification of a pulmonary surfactant-associated protein of molecular weight $=6,000$ Daltons. Pediatr Res 20:744-749

24. Heinrikson RL, Meredith SC 1984 Amino acid analysis by reverse-phase high performance liquid chromatography: precolumn derivatization with phenylisothiocyanate. Anal Biochem 136:65-74

25. Bidlingmeyer BA. Cohen SA. Tarvin TL 1984 Rapid analysis of amino acids using pre-column derivatization. J Chromatogr 336:93-104

26. Edman P, Begg G 1967 A protein sequenator. Eur J Biochem 1:80-91

27. Hewick RM, Hunkapiller MW, Hood LE, Dreyer WJ 1981 A gas-liquid solid phase peptide and protein sequenator. J Biol Chem 256:7990-7997

28. Olafson RW, Rink U, Kielland S. Yu SH, Chung J, Harding PG, Possmayer F 1987 Protein sequence analysis studies on the low molecular weight hydrophobic proteins associated with bovine pulmonary surfactant. Biochem Biophys Res Commun 148:1406-1411

29. Weaver TE, Sarin VK. Sawtell N, Hull WM, Whitsett JA 1988 Identification of surfactant proteolipid SP-B in human surfactant and fetal lung. $J$ Appl Physiol 65:982-987

30. Hallman M, Pitkanen O, Merritt TA, Arjomaa P 1989 Surfactant metabolism in the respiratory distress syndrome. In: Surfactant Treatment of Lung Diseases. Report of the 96th Ross Conference on Pediatric Research. Ross Laboratories, Columbus, OH, pp 69-75

31. Ballard PL, Hawgood S, Liley H, Wellenstein G, Gonzales LW, Benson B, Cordell B, White RT 1986 Regulation of pulmonary surfactant apoprotein SP 28-36 gene in fetal human lung. Proc Natl Acad Sci USA 83:9527-9531 
32. Whitsett JA, Pilot $\Upsilon$, Clark JC, Weaver TE 1987 Induction of surfactant protein in fetal lung. J Biol Chem 262:5256-5261

33. Khoor A, Gray ME, Benn S, Stahlman MT 1991 Expression of surfactant protein A (SP-A) gene in the developing human respiratory system as detected by in situ hybridization. Pediatr Res 29:322A (abstr)

34. Slavkin HC, Johnson R, Oliver P, Bringes $P$, Don-Wheeler G, Mayo M, Whitsett JA 1989 Lamellar body formation precedes pulmonary surfactant apoprotein expression during embryonic mouse lung development in vivo and in vitro. Differentiation 41:223-236

35. Cruz AC, Buhi WC, Birk SA, Spellacy WN 1976 Respiratory distress syndrome with mature lecithin/sphingomyelin ratios: diabetes mellitus and low Apgar scores. Am J Obstet Gynecol 126:78-82

36. Mueller-Heuback E, Caritis SN, Edelstone DI, Turner JH 1978 Lecithin/ sphringomyelin ratio in amniotic fluid and its value for the prediction of neonatal respiratory distress syndrome in pregnant diabetic women. Am $J$ Obstet Gynecol 130:28-34

37. Katyal SL, Amenta JS, Singh G, Silverman JA 1984 Deficient lung surfactant apoproteins in amniotic fluid with mature phospholipid profile from diabetic pregnancies. Am J Obstet Gynecol 148:48-53

38. Hallman M, Arjomaa P, Hoppu K, Teramo K, Akino T 1989 Surfactant proteins in the diagnosis of fetal lung maturity. II. The $35 \mathrm{kd}$ protein and phospholipids in complicated pregnancy. Am J Obstet Gynecol 161:965969
39. Curet LB, Olson RW, Schneider JM, Zachman RD 1979 Effect of diabetes mellitus on amniotic fluid lecithin/sphingomyelin ratio and respiratory distress syndrome. Am J Obstet Gynecol 135:10-13

40. Liley HG, White RT, Warr RG, Benson BJ, Hawgood S, Ballard PL 1989 Regulation of messenger RNAs for the hydrophobic surfactant proteins in human lung. J Clin Invest 83:1191-1197

41. Whitsett JA, Weaver TE, Clark JC, Sawtell N, Glasser SW, Korfhagen TR, Hull WM 1987 Glucocorticoid enhances surfactant proteolipid Phe and pVal synthesis and RNA in fetal lung. J Biol Chem 262:15618-15623

42. Lehtovicta $P$, Forss $M 1978$ The acute effect of smoking on intervillous blood flow of the placenta. Br J Obstet Gynecol 85:729-731

43. Ross S, Naeye RL 1981 Racial and environmental influences on fetal lung maturation. Pediatrics 68:790-795

44. Fadel HE, Saad SA, Nelson GH, Davis HC 1989 Effect of fetal sex and race on amniotic fluid lecithin concentration. Int J Gynecol Obstet 29:125-129

45. Collaborative Group on Antenatal Steroid Therapy 1981 Effect of antenatal dexamethasone administration on the prevention of respiratory distress syndrome. Am J Obstet Gynecol 141:276-287

46. Farrell PM, Wood RE 1976 Epidemiology of hyaline membrane disease in the United States: analysis of national mortality statistics. Pediatrics 58:167-176

47. Fujikura T, Froehlich LA 1966 The influence of race and other factors on pulmonary hyaline membranes. Am J Obstet Gynecol 95:572-578

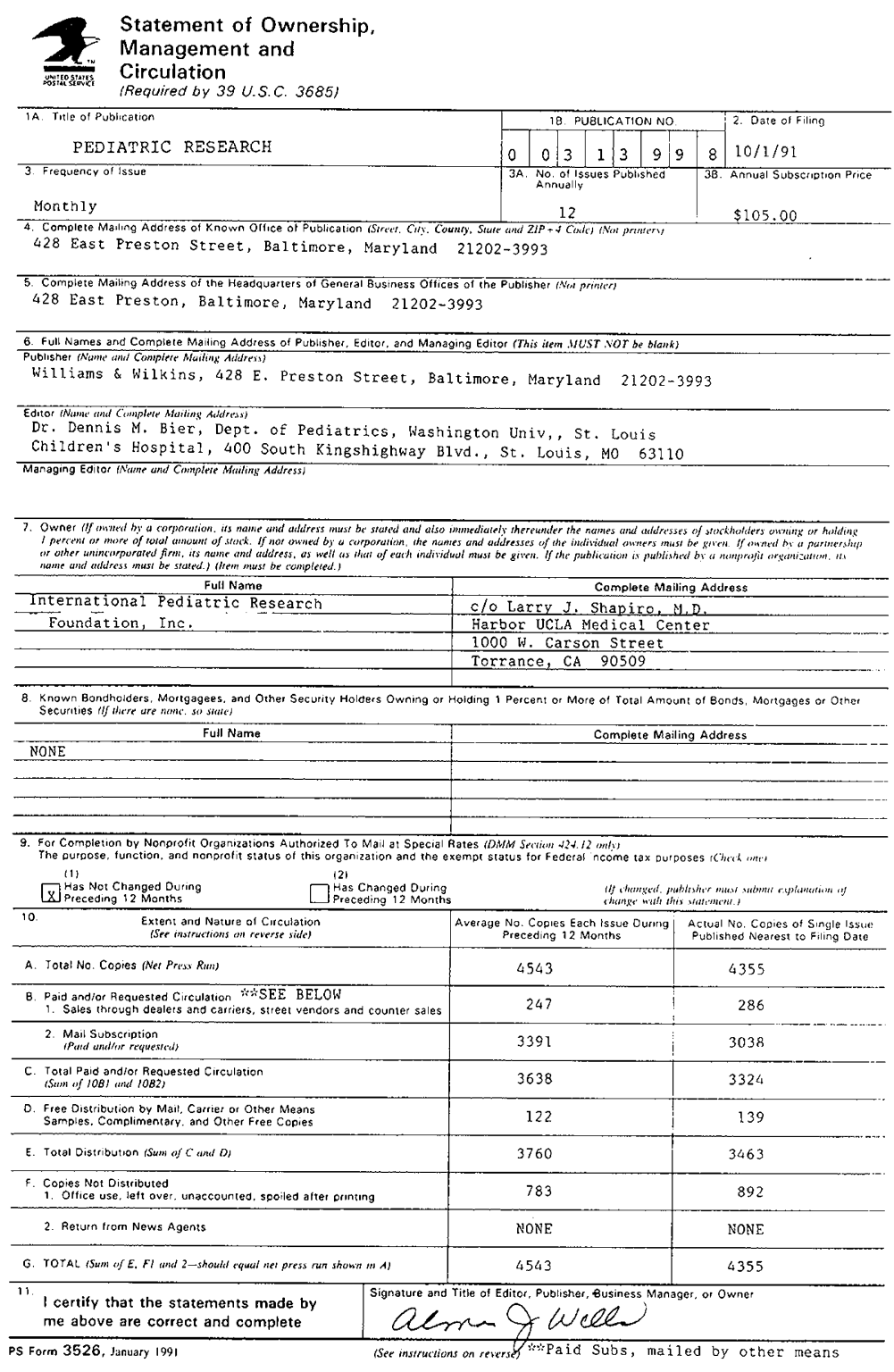

